\title{
Stereoselective Addition of Nucleophiles to Aziridinyl-2-carboxaldimine ${ }^{\dagger}$
}

\author{
Sang-Woo Kim, ${ }^{\text {a,b }}$ Heui-Yoon Noh, ${ }^{\text {a,b }}$ Seong In Paek, ${ }^{a}$ Hyun-Joon Ha, ${ }^{\text {ab, }}$ \\ "Department of Chemistry, Hankuk Lniversity of Foreign Studies, Yongin, Kinthggi-Do 449-719, Korea \\ ${ }^{6}$ Center for Bioactive Holecular Hybrids, Ionsei University, Seoul 120-749, Korea \\ 'Department of Chemistry, Sogang Lniversity, Seoul 121-742, Korea
}

Received Mav 10, 2004

Key Words : Stereoselectivity, Nucleophiles. Addition, Aziridinyl-2-carboxaldimine

Commercial success to produce both enantiomers of aziridine-2-carboxylates in optically pure forms prompts us to extend their sy'nthetic utilities for the preparation of enantiopure nitrogen containing molecules. ${ }^{1}$ In last few years we have studied with chiral aziridine-2-carboxylates to provide enantiomerically pure $\alpha$ - or $\beta$-amino ester and their derivatives. ${ }^{1.2}$ Sy $y$ thetic study has been extended to constnuct diamine compounds based on the reaction with the substrate. aziridinyl-2-carboxaldimine. Recently we successfully prepared aminomethylaziridine and 4.5-disubstitued imidazolidin-2-ones by the addition of organomagnesium reagents to aziridinyl-2-carboxaldimine. ${ }^{3}$ The additions of alkyl- and ary'magnesium reagents to the chiral $\left[1^{\prime}(R)-\alpha\right.$ methylbenzyl]aziridine-2(R)-carboxaldimine were highly stereoselective in most cases with chelation controlled transition states. The subsequent treatment of theses adducts with triphosgen and $\mathrm{NaH}$ afforded enantiopure 5-alhyl- or 5aryl-4-chloromethylimidazolidin-2-ones.

The utility of imines can be expanded by the addition of the nucleophiles other than organometallic reagents as shown in Scheme 1. In this report we would like to describe the recent success to introduce carbon nucleophiles other than alky metal reagents and their stereochemical outcomes with the mechanistic implications.

The addition of nitrile to imine as in Strecker reaction was achieved using cyanotrimethylsilane (4) that reacted with activated imines. ${ }^{+}$The substrate we used. $\left[1^{\prime}(R)-\alpha\right.$-methy'benzy'l]aziridine-2(R)-carboxaldimine (1) was inert without any additives. Reaction in $\mathrm{CH}_{3} \mathrm{Cl}_{2}$ with $50 \mathrm{~mol} \%$ of $\mathrm{BF}_{3} \cdot \mathrm{OEt}_{2}$ at room temperature in 3 hr yielded the products as a diastereomeric mixture (5 and 6 ) with the ratio of $69: 31$ in $91 \%$ yield (entry 1). Two diastereomers were inseparable by chromatography and treated with triphosgen and $\mathrm{NaH}$ in

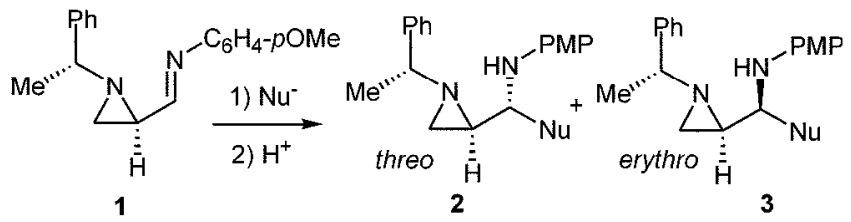

Scheme 1

Dedicated to protessor Yong Hae Kim on the occasion of his 65th birthday.

Co-Corresponding Authors: H.-T. Ha (lijhaghuts.ackr). W. K. Lee (Wonkooiag sogang.ac.kr)
Table 1 . The addition of nucleophiles to chiral ( $p$-methoxypheny $\mathrm{l}$ $\left[l^{\prime}(R)\right.$ - $\alpha$-methylbenzyl]aziridine-2(R)-ylmethylene]amine

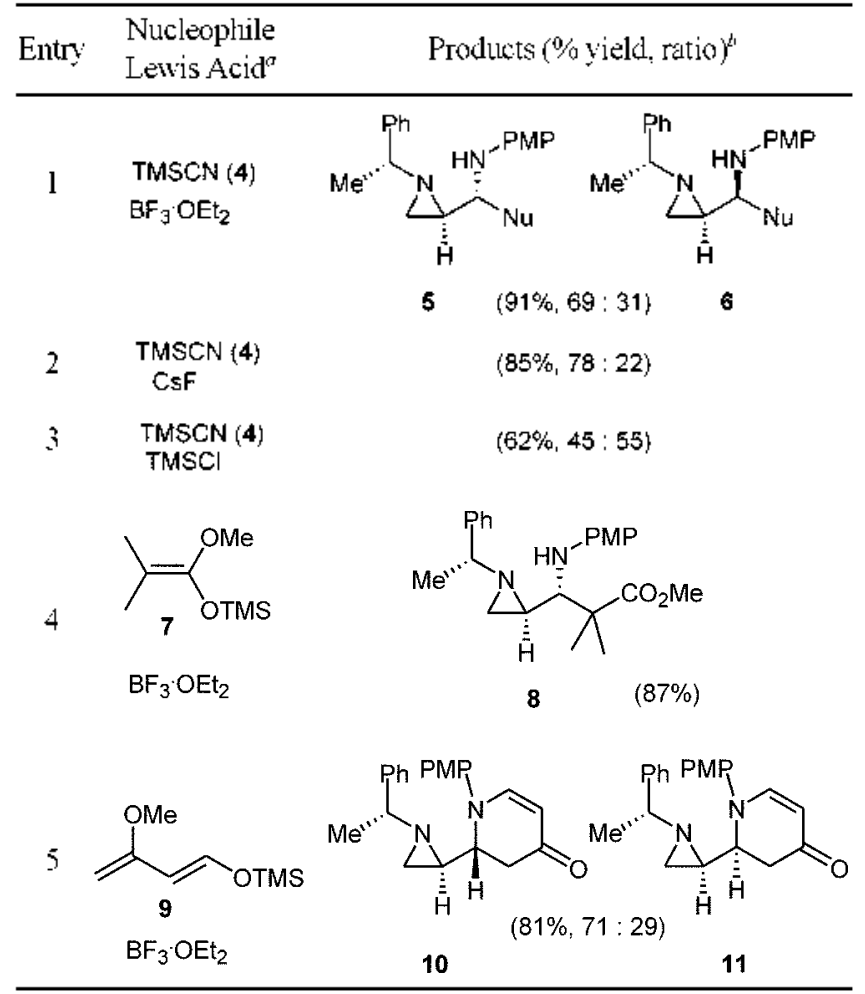

o.5 Mole equivalent of Lewis acid was added. "Yields were not optimized. The ratio was determined by ${ }^{1} \mathrm{H}$ NMR spectrum.

THF to yield enantiopure 5-cyano-4-chloromethylimidazolidin-2-ones. The stereochemistry of two products were determined by the comparison of coupling constant of two imidazoline ring protons at $\mathrm{C}-3$ and $\mathrm{C}-4$. The coupling constant was observed as $2.6 \mathrm{~Hz}$ for the major product and $7.5 \mathrm{~Hz}$ for the minor product which were corresponding to trans and cis configurations respectively. ${ }^{3 . i}$ This informed us that the major product is threo isomer from re face attack of the coming nucleophile to the substrate. Trials to improve the diastereoselectivity by changing Lewis acids such as $\mathrm{ZnCl}_{2}$. $\mathrm{Sc}(\mathrm{OTf})_{3}$. Ti $(\mathrm{O} i-\mathrm{Pr})_{4}$. TMSTf. $\mathrm{CeCl}_{3}$ were not successful to show similar stereoselectivity in a little lower yield. When we used CsF that is known to be a good cataly'st ${ }^{\text {tc }}$ in the addition of imine. the reaction produced a little better ratio as $78: 22$ in $75 \%$ yield (entry 2). It is also noteworthy that the reaction with TMSCl as an additive gave 
products with the ratio of $45: 55$ in $62 \%$ yield (entry 3 ). Changing Lewis acid to Lewis base such as $\mathrm{PPh}_{3}$ and $\mathrm{P}(\mathrm{OPh})_{3}$ did not improve the reaction at all and instead the reactions becante sluggish.

Another nucleophile ketene silyl acetal ${ }^{7}(7)$ was added to $\left[l^{\prime}(R)\right.$ - $\alpha$-methy lbenzyl]aziridine-2(R)-carboxaldimine (1) in the presence of $50 \mathrm{~mol} \%$ of $\mathrm{BF}_{3} \cdot \mathrm{OEt}_{2}$ to afford $\beta$ aminocarboxylated (8) with aziridine ring conserved (entry 4). The stereochemistry of the reaction product obtained as a single isomer was also determined in the same manuer as for the entry 1 after the conversion to the corresponding 4 chloromethylimidazolidin-2-ones. The coupling constant of two inidazolin-2-one ring protons at $\mathrm{C}-3$ and $\mathrm{C}-4$ was observed as $2.2 \mathrm{~Hz}$ which indicated trans configuration to show the same diastereoselectivity as with other nucleophiles. Searching for other isomeric reaction product was not successful to imply the addition reaction of ketene silyl acetal (7) was highly stereoselective. The success of the addition of ketene silyl acetal prompted us to expand the reaction with another electron rich nucleophile 3-methosytrimethylsilyloxybutadiene (9) known as Danishefsky diene. ${ }^{\mathrm{S}^{\circ}}$ The reaction with the additive. $50 \mathrm{~mol} \% \mathrm{BF}_{3} \cdot \mathrm{OEt}_{\dot{2}}$. was successful to give 4-oxopiperidines as a diastereomeric mixture in $75 \%$ yield. Formation of cyclic adducts 4 oxopiperidines would be explained by the addition of 3 . methoxy trimethylsily loxybutadiene as a nucleophile to imine followed by cyclization. The same reaction product could be obtained by aza-Diels Alder reaction between imine and 3-methoxytrimethylsily loxybutadiene as an azadiene and a dienophile. Two diastereomeric products (10 and 11) were separated by silica gel chromatography. Selective removal ${ }^{1 / 2}$ of PMP by treatment of the adduct with $\mathrm{CAN}$ in $\mathrm{CH}_{3} \mathrm{CN}$ was not successful and an unidentified mixture was obtained. Therefore, we could not assign the right stereochenistry of the products at this moment however tentative assignment would be possible on the basis of the previous results as shown in the Table 1 as a major (10) and minor product (11)

All of the addition reactions to ( $p$-methoxy phenyl)- $\left[l^{\prime}(R)\right.$ $\alpha$-methylbenzyl]aziridine-2(R)-carboxaldimine (1) with various nucleophiles including the addition of alkyl or arylmetal reagents yielded threo products that is coming from chelation controlled transition state as $\mathbf{A}$ in Figure 1. The Lewis acid $\mathrm{BF}_{3} \cdot \mathrm{OEt}_{2}$ was not only to activate the imine but to chelate the molecule with two nitrogens of the substrate. ${ }^{3}$ Therefore. the transition state becomes rigid enough and the coming nucleophile attacks the substrate from $r e$ face more favorably than from si face. This rigid transition state is supported by the observation of the strong binding between boron and aziridine ring nitrogen in a single crystal structure of dicyano[[(1R)-(1-phenylethỵl)aziridin-2-yl]-methanolato- $O, N$ ] boron (B) ${ }^{11}$

In conclusion. the addition of various nucleophiles to enantiomerically pure ( $p$-methoxypheny 1$)-\left[1^{\prime}(R)-\alpha\right.$-methylbenzy'l]aziridin-2(R)-y lmethỵlenejamine was successful in

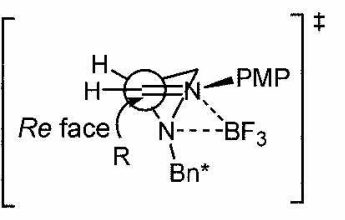

(A)

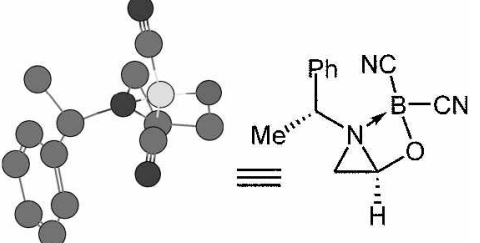

(B)
Figure 1. The possible transition state to lead the major isomer of the nucleophilic addition from $r$ e face to [l'(R)- $\alpha$-methylbenzy $l]-$ aziridine-2(R)-carboxaldimine (A) and the X-ray structure of dicyanol|( $(R)$-(l-phenylethyl)-aziridin-2-yl]-methanolato- $O, N]$ boron (B).

highly stereoselective manner to give 2-aminomethylaziridine in the presence of $\mathrm{BF}_{2} \mathrm{OEt}_{2}$.

Acknowledgements. We gratefully acknowledge the financial support of the following institutions: Hankuk University of Foreign Studies (2004), the Korea Science and Engineering Foundation (R01-2000-000-00048-0 to $\mathrm{HJH}$ and R14-2002-045-01002- 0 to WKL), and the Korea Research Foundation (KRF-2002-070-C00060 to WKL).

\section{References}

1. Lee. W.-K.: Ha. H.-J. Aldrichimica Acta 2003, 36. 57.

2. For review see: (a) Sweeney. J. B. Chem. Soc. Ren 2012. 31. 247 (b) Zwanenburg. B.: ten Holte. P. In Stereoselective Hetercowic Chentistry III: Metz. P.. Ed: Springer: Berlin. 2001. pp 93-124. (c) M'Coull. W. Davis, F. A. Symthesis 2000. 1347 . (d) Osborn, H. M. I.: Sweeney, J. B.; Tetrahedron: Asymmen 1997, 8, 1693 . (e) Pearson. W. H: Lian. B. W: Bergmeier, S. C. In Comprehensive Heterocyclic Chemison II. Padwa. A.. Ed.: Pergamon Press: New York. 1996: Vol. IA. p I. (f) Tanner. D. Angew. Chem, Int Ed. Engl. 1994. 33.599

3. Suh. M.-J, : Kim. S. W.: Beak. S. I.; Ha, H.-J.: Lee. W.-K. Swnten 2004. 489 .

4. (a) Kobayashi, S.: Ishitani, H.: Ueno, M. Synlett 1997, 115 . (b) Meyer. A. G.: Gleason. T. L.: Yoon. T.: Kung. D. W. J. Am Chem. Soc. 1997. 119. 656. (c) Li. B.-F.: Yuan1. K.: Zhan1g. M.-T.: Wu. H.: Dai. L.-X.: Wang. Q. R.: Hou. X.-L. J. Ong Chem. 2003. 68. 6264.

5. Sin. T. B.: Kang. S. H.; Lee. K. S.; Lee, W. K.: Yun, H.: Dong. Y.: Ha. H.-J. J. Org Chem 2003, 68, 104-108.

6. Park, C. S; Kim, M. S, Lee, W. K, Ha, H.-J. J. Org. Chem 2003. 68.43 .

7. (a) Akiyama. T: Itoh. T.: Fuchibe. K. Sinlett 2004. 489. (b) Wenzel. A. G.: Jabobset1. E. N. J. Ant Chent Soc. 2002. 124. 12964. (c) Shimizu. M.: Itohara, S.: Hase. E.: Chem. Conmum. 2001. 2318 .

8. (a) Waldman, H. Angew: Chem. Int. Ed. Engl 1998, 27, 274. (b) Bromidge. S.: Wilson. P. C.: Whiting. A. Tetrahdron Lett. 1998 39.8905 (c) Ishimara. K.: Kjima. T. J. Org. Chent 2000.65 .8395$. (c) Yulan. Y.: Ding. K. Ong. Lett. 2002. +. 3309

9. Ha. H.J.; Choi. C.-J; Ahn. Y.-G.: Yoon, H.; Dong. Y.; Lee. W. K. J. Org. Chem 2000,65,8384 and reterences are cited therein.

10. (a) Shimizu, M.: Suzuki. I.; Makino. H. Sylett 2003. 1635. (b) Bhattarai. K.: Cainelli. G.: Panunzio. M. Synlett 1990. 229. (c) Jacob. P.: Callery. P. S.: Shulgin. A. T.: Castagnoli. N. J. Org. Chent 1976. H1.3627.

11. Dong. Y: Yun, H.; Park. C. S.: Lee. W.-K.; Ha. H.-J. Acta Cnstal. C 2003, 59.659 . 